Journal: Discourse, Context \& Media

Elsevier reference: DCM172

PII: S2211-6958(16)30140-4

DOI: $10.1016 /$ j.dcm.2017.06.001

\title{
The roles of tagging in the online curation of photographs
}

\author{
David Barton
}

\begin{abstract}
This paper explores the variety of uses people make of the tagging feature on the photo-sharing site Flickr. The site developers intended uses are primarily to build a taxonomy to make the images on the site easily searchable. Data from examples of Flickr tags and interviews with selected users reveal that some tagging fits with this aim, whilst other uses challenge and subvert the intended uses. Tagging is used to do at least the following: identifying existing information in a photo; adding relevant new information; expressing affective stance towards the images; addressing specific audiences; making unrelated 'asides'; and for creative play.

The discussion is then broadened by examining a dispute between Flickr and its users about changes being made to the site: this act as a 'telling case' (Mitchell, 1984) as people articulate what the site enables them to do and what it hinders. The dispute generated a thread of more than 29,000 comments, making a corpus of 1,774,401 words. Using corpus linguistics tools the paper demonstrates how users contribute to curating this site, including their uses of tagging. Steps involved in curating the site are identified, including a focus on verbs of curation. Overall, the paper contributes to the analysis of a set of 'new' literacy practices and to understanding digital curation. The methods of the two studies reported here productively combine detailed methods of qualitative research with the breadth of quantitative analysis.
\end{abstract}

Key words: Tagging, Flickr, Curation, Taxonomy, Online, Practices.

\section{Introduction}

The photo-sharing site Flickr was an early example of a site where tagging by users was encouraged. This paper explores the range of creative uses people have made of the tagging feature on Flickr over time and the extent to which this can be seen as a shift in power from the site developers to the users. The approach, which involves the analysis of texts and of practices, can best be described as ethnographically informed discourse analysis and the interest in tags is part of a broader study of people's everyday digital practices. (See Barton \& Lee 2013 for further details of the general approach.) In section 3 of this paper the focus turns to an online dispute between the developers of this site and its users, drawing on corpus analysis to understand the dynamics of this dispute and discussing it in terms of a disagreement about the curation of the site. 
The first study reported here shows how tags provide a writing space with particular affordances which users build upon. The study discusses people's purposes when tagging, how tags are used as more than just as parts of a taxonomy or folksonomy and what is lost when discussing tags away from the pages where they are being used. A taxonomy is a classification into categories, usually in areas of scientific expertise such as biology or linguistics. However, what we see on Flickr is a 'folksonomy' where rather than being created by an outside expert, the categories are provided by the users. The folksonomy comes from collating tags from a large number individual people's tags. A key difference between the two is that any search is utilising people's own words, rather than those imposed by an outside expert. Whilst ways of classifying are important, as we will see below, people can do much more with tagging than just contributing to a folksonomy.

\section{Tags as text on Flickr}

In this study evidence about tagging practices comes primarily by examining the texts, that is, the web pages containing the tags. This was supplemented by online interviews with some of the creators of the web pages. By way of introduction to the topic, it is useful to begin with a general description of tagging. An initial point to emphasise is that tagging works differently on different sites. In an early study of tagging, Marlow et al (2006) examine how Delicious (formerly del.icio.us) differs from Flickr. They identify a set of 7 aspects of site design which affect tagging practices. The 2 sites vary on what can be tagged and who can tag. By default any member of Flickr can add a tag to any photo. Sites vary in what support there is for tagging, for example whether there is a limited set of possible tags and how the tags are presented. Some tags may be automatically provided, such as date and make of camera. Marlow et al show how Delicious and Flickr differ on all these dimensions. Further differences can easily be seen by examining other sites such as YouTube, Twitter, Pinterest and Instagram. In addition sites change over time and, as we will see in the examples below, what was simple can suddenly become very difficult and vice versa. A seemingly small change can make a big difference, as will be clear when discussing the changes made to Flickr in 2013, below.

Underlying the differences between sites are the possibilities which the designers envisage for each site. People act within these possibilities, taking up some opportunities, ignoring others and creating new activities which the designers never intended. It is this creative space between the designer and the user where the unexpected can happen. This constitutes the affordances of tagging. In fact there is a remarkable range of possibilities on Flickr, many of which are hardly taken up, but at the same time there are strong constraints on what is possible. For example, although by default anyone can add tags, in practice most tags are created by the photographer and although they can add tags at any time people tend to create the tags when they initially upload the photo.

Even on Flickr, a site devoted to visual images, there can be a great deal of language surrounding the images. When uploading a photo to Flickr the user is invited to add written titles, descriptions, tags, and more, each having its specific writing space, so each photo can be surrounded by language serving many functions. At the time of collecting this data, the title of the photo was in a large bold font and superimposed over 
the bottom left hand side of the image. Below in a smaller font was the description space which can be empty or can contain several pages of text. Tags appear on the right hand side of the photo page as left to right text with a space between each tag.

Looking at the tags used on Flickr in this study, it is clear that there are all sorts of words including technical terms, dialect words, obscure words, abstractions and abbreviations, and many written languages are represented. All parts of speech are there. There is considerable deixis, such as 'here' and 'there', although such words are not very good for creating a taxonomy as their reference is constantly shifting. The deictic pronoun 'me' is used nearly 4 million times. Some details of the image are automatically added elsewhere on the page, such as when and where the photo was taken, and details about the camera and its settings. Prior to this if people wanted to display this information they had to add it as tags.

Another early study comparing Flickr and Delicious, Guy \& Tonkin (2006) identifies the main criticisms aimed at taggers, that their tags are often ambiguous, overly personalised and inexact. Studies are critical of tags which are only used once, as well as the use of 'nonsense' tags designed as unique markers that are shared between friends. The result is seen as an uncontrolled and chaotic set of tagging terms that do not support general searching. Guy \& Tonkin found 40\% of Flickr tags were either misspelt, from a language not understood by the dictionary software used, or compound words consisting of more than two words. Ironically, given the current ubiquity of hashtags on twitter and many other sites, one of the complaints then was that 'Symbols such as \# were used at the beginning of tags, probably... to list the tags at the top of an alphabetical listing.' Overall Guy \& Tonkin saw the problem for tagging systems as being the way they 'are trying to serve two masters at once: the personal collection, and the collective collection.' Starting from people's actual tagging practices provides a richer view.

Turning to the initial study reported here, data from a study of the practices of 30 multilingual Flickr users (Lee \& Barton, 2011) was reanalysed with a focus on tags and tagging and provides users' views of tagging (as reported in Barton, 2015a). Firstly, people were emphatic that they use different sites for different purposes: Flickr was often used to display and to document, and for the photos to have a lasting presence. It was a platform for serious exchanges between photographers, including professionals. In contrast the users we interviewed reported that for them Facebook photos were often more transient, were consumed quickly and quality was less important. Most of the multilingual users of Flickr had tags in more than one language. For example, one user stated:

1. I try to fit all the tags both in English (universalism) and in Spanish (my immediate Flickr public) and, since I know a little French, I put the French word when I remember it. 
Here the multilingual Flickr user is using their languages strategically to address different audiences and to project specific identities. Often the specific aim was to get more hits:

2. I want to get more views of my photos. I assume there might be lots of people in mainland China that might search for Queen's Pier photos, so I want my photos to come up in the search results when someone searches for Queen's Pier in simplified Chinese characters.

This is a way of utilising the affordances of Flickr to make their site more popular. Sometimes there was direct translation, whilst at other times people put different information in different languages:

3. When I post thinking about someone, a close friend or a known follower, I tend to post in Spanish.... If I tag in Spanish, it has to be for a local (or personal, e.g. 'torollo') non translatable term.

Some tags would only be recognisable to knowledgeable insiders, such as the tags ' 365 ' used to indicate that the photo was part of a project of posting a photo a day for a year. Sometimes tags would be used to repeat information in the image. At other times the tags introduced new information needed to make sense of the image. When interviewing people as they examine a Flickr page we have observed that they often go back and forth between image and language and that they use the tags as part of their reading paths to understand more about the photo. As well as being good examples of multimodal meaning making, these translingual practices (Wei, 2011; Lee 2017) demonstrate the many ways people deploy their multilingual resources.

Another point to stress is that there is a 'grammar' to the tags: that is, taken together these tags have a meaning which they don't have when considered separately. The tags can be used - in conjunction with the language and image on the rest of the page - to tell a story. To demonstrate this I will work through a rich example taken from a later study. This is of someone doing a 365 project. On the first day of her 365 project she used a photo of a garden gate. The photo has the title '...do I have to go? $(1 / 365)$ ' with the short description beneath: ' $26^{\text {th }}$ November ...dreaded trip to the dentist'. The accompanying tags provide more detail of the day.

\section{[PLEASE KEEP EXISTING LAYOUT]}

4. Project365 365 gate leaving going out

Dentist torture hate fear garden path

Teeth tooth pain dread appointment

Canon eos 400D my day snapshot glance 
Day one first starting digging my heels in

Countryside rural Bungay Suffolk me

Life stress everyday myeverydaylife

Note how this is laid out with 4 or 5 tags to a line. There is a strong narrative here linking up the two activities of doing the 365 photo project and the visit to the dentist, both being challenging, and the tags can be read as a small story. This idea of the 365 project being a tough challenge is common in the 365 data. There are many different sorts of tags on this photo page: there are several phrases, including 'garden path' and 'myeverydaylife'. Some of these tags are particular to the photographer, but several of the unconventional ones, such as 'adaywithoutrain', are also used by others. Overall in the tags there are many phrases and whole sentences. These are comments, explanations and asides, all contributing to telling a story in a humorous way. There are also exclamations such as 'eeeeeeeek!'. Here the photographer is not using tags as folksonomic hyperlinks to aid searching for similar photos; nor is she contributing to creating an overview of a vernacular structure of knowledge. Many tags are being used individually to express a contingent meaning and not to link outwards. In particular the affordances of the layout are taken advantage of: Tags are in lines wide enough for 4 or 5 tags which is also good for writing poetry and telling stories. Earlier individual tags had been in a vertical list and the sense of different sentences would not have worked.

Looking at broader data covering the people in the original study, everyone had some tags which would be regarded as deviant in terms of not contributing to making a taxonomy, but to the users could be seen as playful. The most common form of this nonstandard tagging, which they all had examples of, was of multiword tags, such as 'uglybird' and 'gloomysunday'. These are plausible concepts which others might use. Eighteen users also had ones which could be regarded as more idiosyncratic. Often they were short phrases such as 'notmycat'. Several even had longer phrases or sentences as in 'yesilikethatsongsomuch'. Half of the Flickr users had phrases which linked them to particular Flickr groups, such as the tag '365days'. Nearly half of the users had tags with initials, mixtures of numbers and words, or they played with spelling or punctuation, as in '5elements', and 'aaaa'. At least 5 people had a few multilingual tags like 'mujerwoman' and some tags were intertextual references to songs or other external material. The garden gate example demonstrates many of the difficulties with seeing tags as purely providing a taxonomy and we will return to the additional uses of tagging at the end of this paper.

To summarise so far, this investigation has established that on Flickr the writing space of tagging is used to do at least the following: identifying existing information in a photo; adding new information; expressing affective stance towards the images; addressing specific audiences, making unrelated 'asides'; and for play. This wide variety of uses demonstrates that people are active meaning makers online; they are designers who creatively draw on whatever resources are available. Overall, tags cannot be understood fully on their own but they need to be considered in relation to each other and as part of overall meaning-making on the page. The site developers' intended uses are primarily to build a taxonomy to make the site easily searchable. Data from examples of tags and from interviews with selected Flickr members reveal that some 
uses of the tagging space on Flickr fit with this aim, whilst other uses challenge and subvert the intended uses of the tagging space.

\section{Tags as practices: How people talk about tagging in an online dispute}

We now extend the discussion by examining a rich source of data in order to explore more about people's purposes and intentions when tagging. Data is taken from a dispute between Flickr and its users. In May 2013 Yahoo made major changes to the layout of the site which immediately provoked a strong and largely negative reaction. Within a short time there were more than 29,000 comments. These provide a large corpus of people commenting on their own use of the site. This can act as a 'telling case' (Mitchell, 1984) as people articulate in greater depth what the site enables them to do and what it hinders, including their discussions about the role of tagging. The comments provided a corpus of 1,774,401 words. This was interrogated with straightforward corpus linguistics tools and this section argues that an important practice which users participate in is contributing to curating the internet. Different sorts of digital curation are explored and the steps involved in curating the site are set out. I examine this corpus in order to uncover why the changes were so important to the users. In juxtaposing this data with the data from the earlier study it is possible to combine the intensity and detail of qualitative research with the breadth and magnitude of quantitative research, providing detail while at the same time drawing on the full corpus of more than a million words.

So far the research has been qualitative in nature and not drawing upon all the data. It would have been possible to continue this approach and to get word searches on qualitative software such as AtlasTi but the corpus software used, Antconc, gave better layout of results and more tools for interrogating the data in different ways. Elsewhere (Barton, 2015b), this corpus of data has been used to examine affect, how users express like and dislike towards the site. (See Baker, 2010, for more on using corpus linguistics in sociolinguistic studies.) ${ }^{1}$.

Turning to the changes to Flickr made in 2013, firstly, there had been no prior notice of the changes and this is how Yahoo announced them on the website:

5. A better, brighter Flickr

In the beginning, Flickr innovated the way people share and discover photos.

Today, we are shifting the photo-sharing landscape again. We're releasing a

Flickr that's more spectacular, much bigger, and one you can take anywhere.

Biggr. A free terabyte of space...

Spectaculr. A new, beautiful experience for your photos

We want Flickr to be the most amazing community.....

This positive, breezy Californian enthusiasm was quickly punctured by the first 10 responses from Flickr users:

6. WoW!

\footnotetext{
${ }^{1}$ I am grateful to Mark McGlashan for preparing the corpus.
} 
7. I just clicked on a pic - yuk!

I don't like going to the black page with the comments lost at the bottom

8. Blimey!

9. Would have been a really nice thing to ask 'before' changing it? Would also really like some customizing options or opt out of some of the new stuff... my internet isn't the fastest and it takes forever now to load my photostream...

10. Change it back!!

11. this. is. FUCKING. HIDEOUS.

12. Hi, following the change to black backgrounds, how do I cancel my Pro account and get a full refund?

13. What in the hell is this confused mess of crap???

And I can't access my photostream... all I get is the eternally spinning and cursed blue and pink balls after signing in.

14. What [6] said

15. The pictures are lost in this huge chunk of black -- and fiddly clicks to send the picture to someone...

Couldn't we have been asked?

It is clear that there was a wide range of complaints, including complaints about the new layout, about difficulties linking to other parts of the website, a preference for the earlier website and issues about lack of consultation, as well as general negative reactions. This tone continued for 29,000 comments made in a short period of time. Some comments were a few words long, like these early ones; others were more extensive and users were reflexive about their uses of Flickr and its value to them.

Where people mentioned tagging it was often in the context of other activities, as in the following examples, and was about how some aspects were being made more difficult by the changes:

16. I have also invested YEARS in organizing, tagging and documenting photos on my Flickr site.

17. This is awful. I have devoted a lot of time to creating sets, linking them to groups, and adding tags

The point was made, repeatedly, that the users are doing a lot of work and are creating the content of Flickr, as in this extensive comment:

18. If you are reading this, Yahoo visionaries, you do realize that we do everything, don't you? we take the photos. we upload the photos. we tag the photos. we markup the photos. we favorite the photos. we add the photos to groups. we admin the groups. we invite photos to groups. we create sets, collections and galleries. we comment on photos. we create discussions. we respond to discussions.

I'm a fairly active user. in the $6+$ years that I've been a member, and probably a Pro member for most of that time, there have been very few days when i didn't log into my flickr account, whether i had new content to upload or not. i admin dozens of groups, mod a bunch more and am a member of a couple hundred probably. i tag my photos religiously, i add to groups judiciously and in general, i 
try to make my photos accessible, enjoyable to look at, and useful for people searching for an image of something, someone or someplace.

After years of organizing, captioning, commenting, tagging, geotagging, favoriting, editing, etc it is quite a lot of work to move content off Flickr with minimal loss. I will do it if necessary. This also makes it worthwhile to await a concerned response/action from Flickr on the off-chance.

Another user sees this activity as 'giving something back' to the internet community:

19. I have spent countless of hours choosing right images to upload, organizing them in to sets, adding tags and sharing them in to relevant groups. Most of my pictures have been licensed under creative commons attribution -license. I have wanted to give something back to the wider internet community who has written all the open source software I use in my work and has edited resources like wikipedia.

In terms of purpose there are several comments relating the tagging activity to specific purposes, such as teaching:

20. Organization and navigation of my photos: I spent a lot of time organizing my stuff into sets, collections, adding tags etc. Now the photostream page no longer provides a handy shortcut to collections as I had set it up before. Finding specific images uploaded in the past takes much longer now. The icons are all messed up, and set descriptions are a useless mess of mangled code that is impossible to copy/paste from the box that pops up when you hover over them or follow any links they contained. This has made Flickr instantly useless for my lecture preps. I hope it gets fixed. If not, I'll have to find another place to organize my images and descriptions for class use.

These 5 quotes, examples 16-20, are drawing attention to a range of overlapping activities that involved tagging in some ways. These are activities that can be described with verbs like selecting, documenting, organising, gathering, collecting, sharing, interpreting and displaying. Each quote mentions a different combination of activities, but overall they all point to the notion of curation.

\section{Online curation}

The term curation is widespread and is used in many ways in relation to online practices. I want to argue the notion of curation captures an important way of participation in Flickr, and that online curation involves a distinct set of literacy practices. The term's origin is in institutions such as museums, libraries and art galleries and other areas of professional life where exhibitions and collections are seen as curated. It involves these activities of choosing, connecting, classifying, archiving, creating a record. It is about being a producer as well as a consumer. In fact in a wellcited quotation Edward Tufte identifies more than 60 activities whereby people navigate through a world full of information:

select, edit, single out, structure, highlight, group, pair, merge, harmonize, synthesize, focus, organize, condense, reduce, boil down, choose, categorize, catalog, classify, list, abstract, scan, look into, idealize, isolate, discriminate, distinguish, screen, pigeonhole, pick over, sort, integrate, blend, inspect, filter, lump, skip, smooth, chunk, average, approximate, cluster, aggregate, outline, 
summarize, itemize, review, dip into, flip through, browse, glance into, leaf through, skim, refine, enumerate, glean, synopsize... (Tufte, 1990: 50, cited by Bhatt, 2017, and others. See also Ross, 2014, and De Barros, 2015).

These can be seen as aspects of curation and this quote reports on a primarily offline world. Moving it from an offline world to one which fuses the online and the offline is the next step. The idea of digital curation has spread quickly, especially in the context of young people and education, as in Potter \& Gilja (2015), but also with education and adults, as in Bhatt (2017). I am focusing on vernacular uses by people of all ages. Ilana Snyder (2015) discusses digital curation extensively - there are so many activities adding up to online curation and the ways used in different domains, ways which are overlapping but different, for example in the extent to which original creation is important. From her article and the sources she draws upon I identified a set of words contributing to the complex act of curating online, verbs of curation. I have grouped them as 5 overlapping but loosely sequential steps:

Creating - enhance, repurpose, assemble, recontextualise, aggregate

Selecting - filter, choose, gather, collect, assemble, accumulate, desire

Organising - link, archive, catalogue, edit, connect, interpret, manage, classify

Presenting - share, disseminate, display, distribute, recommend,

Interpreting - teach, protect, look after, take charge of, help, editorialise

Creating, the first step, can be central as the Flickr user is often the photographer, assembling their own photos, but this is not always true as there are sites of existing photo collections, or of postcards or other existing images. Choosing and organizing are essential. Alongside this there is a strong social aspect and something has to be done to share and make it public and accessible. The fifth steps captures many overall purposes and how curation may be part of a broader social practice such as teaching or organizing a public collection. The balance of these five steps varies in every situation. In the data from Flickr, the most common terms referred to, the ones which had more than 1000 instances, were 'creating', 'choosing', 'collecting', 'editing', 'sharing' and 'displaying', invoking the first 4 steps. Any site allows or encourages particular aspects of curation. The link to the original museum sense was sometimes invoked:

21. In whatever photostream, there needs to be some space between the pictures. Have you ever been to museum that was this crowded of works? And there needs to be additional information visible, not just on hover, the whole context is missing! Author and title must be visible on photostreams, and in single-Image view, all the information should be on the screen, title, description, tags, map, the first comments as well as the connected sets and groups. All of this was present in the previous layout. Now it's as if we had no communication option except Image files.

The term curation itself was not used very often, but some people had a very strong idea that this is what they have been doing on Flickr, as in these 3 examples:

22. I've spent a lot of time putting together a well-curated set of thousands of historical images from my collection, with detailed descriptions. I received 
hundreds of comments from people who enjoyed viewing them in that format and many requests to reprint as well. We had a great little community going. Now it's just a jumble of images without context. The organization and the professional appearance have been lost. It's really upsetting as I had put a lot of work into this project.

23. I, along with many others, have made flickr a central part of my creative life, investing significant time in carefully curating my photostream and building a network of contacts whose work inspires me and whose opinions I respect. This 'redesign' has destroyed all that and I will be closing my account as soon as I have migrated my stream to ipernity.

24. I feel a little wounded, I have put a lot of effort into sets, collections, and organization, and I love your system. I like curating my own museum, and Flickr is definitely the best platform for photo sharing on the web. I feel the new layout negates the effort I have put in. I feel it makes Flickr worse than before. I will have to wait and see if I can deal with the changes. I can't leave because there is no place else to go. And when you have 10,000+ carefully organized photos, there's no point in making such an effort.

Looking across these quotes it is clear that people talk of tagging within the context of sorting, organising and documenting their photos. We can see that Flickr has always been a site for photography as 'serious leisure' (Cox, Clough \& Marlow, 2008). People also feel that by their contributions they have some ownership of the site and some rights over it, for example the right to be consulted and for their views to be taken account of. These aspects of curation can be seen in the following 3 short quotes:

25. What's going on? - the forced change of a layout is not a fair move. It's like entering your studio and find it to be redecorated \& dysfunctional.

26. ...I lovingly curate my photos....

27. my homepage is no longer a nicely curated gallery but a dumb magazine with dark backgrounds with no titles, no descriptions...

\subsection{Institutional curation online}

One clear way in which Flickr can be seen as a serious site where photos are there as a matter of record and where taxonomy can be seen to be useful is in the area of Flickr Commons where public photo archives are archived (www.flickr.com/commons). Through this Flickr has always encouraged institutional photo collections and efforts to tag them. According to the Flickr commons home page 'The key goal of The Commons is to share hidden treasures from the world's public photography archives' and to provide a way for the public to contribute information and knowledge. It was launched with a project in association with the US Library of Congress photographic collection in 2008. The library, which has more than 15 million images, had very little information about many of its photos and Flickr members were invited to add tags, notes and comments to around 3000 photos. The library only put 3 tags on each photo: 'Library of Congress' along with 2 identifier tags. Here the library was assembling the collection and choosing the images, the first steps of curation, and Flickr members were involved in the organizing stage. The project was highly successful and in 9 months there had been more than 10 million views of the photos and 67,176 tags had been added. The site is 
still being used heavily and the library continues to add a small number of photos each day. Flickr provides three ways for people to add information to posted photos: freeform comments, tags, and notes applied to the pictures themselves. The report on this initial project (Springer 2008) is useful in summarizing what sort of information gets added as comments, tags and notes:

Comments allow viewers to reminisce and share knowledge, increasing the sense of ownership or stewardship that people feel for that content. Often drawing on personal histories, Flickr members have made connections between the past and the present, including memories of farming practices, grandparents' lives, women's roles in World War II, and the changing landscape of local neighborhoods. Sometimes commenters have identified the precise locations of photos and posted pictures of the landscapes as they appear today....

Flickr members also have offered corrections and additions by identifying locations, events, individuals, and precise dates. This data is often supported by accompanying links to articles from the New York Times archive, Wikipedia, and subject-specialized Web sites. After verification by Library staff, information provided by the Flickr community is incorporated into our catalog records.

Within Flickr, tags can be searched separately from the words in photo descriptions. To determine the types of tags that were being added to images, we analyzed the tags in a sample set.......tagging including personal commentary, place names, and tags in multiple languages, in addition to the repetition of LCprovided information.

Notes (annotations left directly on the photos) have some utility, such as pointing out specific persons in a crowd or deciphering the words on a sign or placard.'

It is interesting how tags are combined with comments and notes to provide different sorts of information about the images. The report adds disapprovingly:

Notes are also a means of adding graffiti-type messages and smart-aleck humor to the images, which is a cause for some concern among Flickr members and Library staff.

This social media-type usage of notes can easily be found in other Flickr photos. A fairly randomly chosen photo, from the New Zealand National Library Archive, of an election night crowd in the street in 1931 is covered in notes most of which are completely scurrilous and untaxonomic, including: 'I want a hat exactly like this one', 'I've found Wally', 'Hi MOM', 'Cheese' and much more (https://www.flickr.com/photos/nationallibrarynz commons/3326203787/) This playful, and in some senses creative, use of notes did not help the aim of providing more information about the photos. Nevertheless, as pointed out earlier, it was a reasonably common activity on Flickr more generally. In fact Flickr later dropped notes as a way of tagging parts of photos, maybe as it was not being used as intended, but it has reinstated them more recently.

Different archives have used different ways of engaging users to provide information, usually involving tagging. Turning to another collection, the British Library has more than a million photos on Flickr. One set they have added comes from a project they have called 'the mechanical curator'. This is automatic detection of images which identified that there are more than a million images in their digitised collection of over 65,000 
books from the 17th, 18th and 19th centuries. On each hour every day, the automatic system selects and uploads an image taken at random from these pages of digitised works held at the library. Uploading each photo separately helps ensure that each photo gets attention some paid to it. The images have machine tags from the Library and they also have automatic tagging added by Flickr, as discussed below.

Another collection, the National Maritime Museum in Greenwich, London, contains over 33,000 images and photographs depicting notable ships, trade and empire, astronomy, exploration, navigation and time. The museum joined The Commons on Flickr and invited the public to help interpret their photograph collection. The museum encourages Flickr members to tag their photographs with tags "which describe them best", along with the names of the people and locations. As a different form of curation they also host public groups such as one called 'Beside the Seaside' where users were invited to share their own photographs and to tag them with a place name and to geotag the photos by adding them to a map. In another project users were invited to choose photos from the Museum's collection to be put on display. These examples of 3 different photo collections provide a glimpse of the possibilities for tagging and the different steps in curation which Flickr members are encouraged to participate in. The overall practices of curation are distributed between the library, the Flickr site and Flickr members. This is a dynamic situation and changing.

\section{New directions in tagging on Flickr}

Discussion so far has been mainly about the dispute in May 2013. One frustration throughout has been how little Yahoo responded and engaged with their critics. Nevertheless, they have continued a programme of changes. They still adjust the site layout, which is sometimes approved of by users and sometimes not. There are changes which make Flickr more of a social media site, for example providing a new space for trending tags, making it more like hash tags with its emphasis on popular tags. Yahoo have also given more prominence to 'interestingness', which has been a feature for some time. Notes have been reintroduced, as mentioned above. This effectively encourages tagging parts of a photo, such as a person's name. In these ways tagging is acting more like hash tags on other sites. The move towards emphasizing social media may be a way to attract new audiences to Flickr but is not likely to be welcomed by the disaffected serious photographers who complained about the 2013 changes. There was a current of hostility in the comments towards existing social media sites such as Facebook, which was mentioned by name 1945 times. Examples are:

28. Flickr is not FB! Flickr is not google+, Old Flickr was a community of photographers wanting to share photographs not gossip!!

29. Looks like facebook! If you are going to put freakin' daisies on my homepage, at least let me put one of my own photos!

One last change to be mentioned here is the current development of automatic tagging of Flickr images. It has been possible to add metadata about an image automatically for some time. This has included location of the photo, as well as the time it was taken, the camera model and settings and copyright status. Considerable aspects of the actual content of an image can now be detected and added as automatic tags. For instance, individual people, breeds of animals, and activities such as a wedding can currently be identified by software and the technology is advancing very quickly. These aspects are 
now added to Flickr photos as automatic tags. They are distinguished from user generated tags by being shown in a different colour. This development adds to the taxonomic side of tagging and is likely to be very significant in tagging practices. Currently automatic tagging varies in accuracy and it is not clear how welcome it is to the general user.

To summarise and conclude, there are many things going on in tagging spaces in addition to creating taxonomies. It is not just about folksonomies. A complex picture of tagging practices emerges. Tags are not isolated terms, but they can relate to each other, internally within the tagging space and externally in relation to the whole photo page. Order and layout of the tags can be important and there can be a strong narrative in the tags. People vary in tag usage: some never use them; others make tagging a central part of their pages. Multilingual Flickr users can use the resources of their languages strategically to make meaning when choosing what languages and scripts to put tags in.

People use tags for many expressive purposes. They can be used to express affective stance towards images (see also Lee \& Chau, this volume, on affect). They can be for making 'asides'. Tags can be individual words, phrases and even whole sentences. In what is in many ways a very serious site, there is at the same time a great sense of play on Flickr. In their tagging, people are exhibiting linguistic creativity by inventing new concepts and new lexical items. In a meme-like way, these can get picked up by other users. Finally, in the constant shape shifting of the internet, sites are constantly being redesigned, people are developing their practices and these may include significant changes in how and why people tag images.

Tagging can be an important part of the curation of the Flickr site which users feel they contribute to strongly. We can see the ways in which power is in fact distributed between users and developers and how it is ultimately controlled by the developers. People asserted their power and confronted the developers but at the same time this revealed the limits to users' power. As a last resort users can leave the site and move to another one but they risk losing the infrastructure they have built up over time for organizing their photos and having to start again. The findings of this paper help explain the extremely hostile reaction to the changes in Flickr. The forms of curation revealed by corpus analysis contribute to searchable taxonomies. However, it is broader than this: Returning to the earlier analysis of individual tags, all online design has an element of curation and can in some sense be regarded as curation of the internet. The users who invented new words and phrases and wrote stories in the tagging spaces were also designing their sites in deliberate acts of vernacular curation. Overall this paper contributes to the analysis of a set of digital literacy practices, it identifies patterns of curation and broadens the notion of digital curation. The paper concentrates on everyday or vernacular practices and complements the work which has been done on educational practices. This framework is likely to be of value in analyzing other social media sites such as Twitter, Pinterest and Instagram. It provides a mixed methods approach where discourse analysis is set in the context of ethnographically-informed data. 


\section{References}

Baker, P. (2010) Sociolinguistics and Corpus Linguistics. Edinburgh University Press. Barton (2015a) Tagging on Flickr as a social practice. In R. Jones, A. Chik \& C.Hafner (eds.) Discourse and Digital Practices: Doing discourse analysis in the digital age. London: Routledge. P48-65.

Barton (2015b) Falling out of love with Flickr: Analysis of a conflict between the owners and the users of a global website. Conference paper, The Sociolinguistics of Globalization: (De)centring and (de)standardization. Hong Kong, June.

Barton, D. \& Lee, C. (2013) Language Online: Investigating digital texts and practices. London: Routledge.

Bhatt, Ibrar. (2017). Assignments as controversies: a study of digital literacies in classroom writing. London: Routledge.

Cox, A., Clough, P. \& J. Marlow 2008. Flickr: a first look at user behaviour in the context of photography as serious Leisure, Information Research,13(1).

De Barros, N. 2015 Digital curation as a new literacy: students as potential curators of information on the web. In Gitsaki, C., Gobert, M. \& H, Demirci (eds.) Current Issues in Reading, Writing and visual Literacy: Research and practice, Cambridge Scholars, p285299.

Guy, M. \& Tonkin, E. (2006) Folksonomies: Tidying up Tags? D-Lib Magazine, January 2006, Volume 12 Number 1. (http://www.dlib.org/dlib/january06/guy/01guy.html last accessed 17 Mar 2014)

Lee, C. (2017) Multilingualism Online. London: Routledge.

Lee, C. \& Barton, D. (2011) Constructing Glocal Identities through Multilingual Writing Practices on Flickr.com. International Multilingualism Research Journal, 5(1), 39-59.

Lee, C. \& Chau, D. (forthcoming) Language as pride, love, and hate: Archiving emotions through multilingual Instagram hashtags. Discourse, Context and Media.

Marlow, C., Naaman, M., Boyd, D., \& Davis, M. (2006) HT06, tagging paper, taxonomy, Flickr, academic article, to read. Paper for HT'06, Denmark.

Mitchell, C. J. (1984) 'Case Studies', in R. F. Ellen (ed.) Ethnographic Research: A Guide to General Conduct, pp. 237-41. London: Academic Press.

Potter, J. \& 0. Gilje (2015) Curation as a new literacy practice. E-learning and digital media 12(2) 123-127.

Ross, L. 2014 Language in the Visual Arts: the interplay of text and imagery. Jefferson, NC: McFarland.

Snyder, I. (2015) Discourses of 'curation' in digital times. In R. Jones, A. Chik \& C.Hafner (eds.) Discourse and Digital Practices: Doing discourse analysis in the digital age. London: Routledge. P209-225.

Springer, M., B. Dulabahn, P. Michel, B. Natanson, \& D. Reser, D. Woodward, and H. Zinkham 2008. For the Common Good: The Library of Congress Flickr Pilot Project. Report Summary. Washington: Library of Congress. 
Tufte, E.R. (1990) Envisioning information. Cheshire, CT: Graphics Press.

Wei, L. (2011). 'Moment analysis and translanguaging space: discursive construction of identities by multilingual Chinese youth in Britain'. Journal of Pragmatics, 43, 1222-35. 